\title{
Hepatic and splanchnic nitric oxide activity in patients with cirrhosis
}

\author{
A I Sarela, F M A Mihaimeed, J J Batten, B R Davidson, R T Mathie
}

\begin{abstract}
Background-In animal models of cirrhosis, altered activity of nitric oxide (NO) has been implicated in the pathogenesis of increased intrahepatic portal vascular resistance and abnormal mesenteric vasodilatation.

Aims-To investigate NO activity in the liver and splanchnic vascular bed of patients with cirrhosis.

Methods-Activity of the calcium dependent constitutive and calcium independent inducible isoforms of NO synthase (cNOS and iNOS, respectively) was assayed biochemically in biopsy specimens of liver and a vascular portion of the greater omentum (representative of mesenteric vasculature) obtained from patients with cirrhosis undergoing liver transplantation $(n=14)$ and non-cirrhotic control patients undergoing liver resection for metastases $(n=9)$. The concentration of NO metabolites $\left(\mathrm{NO}_{2}+\mathrm{NO}_{3}\right)$ in portal and peripheral venous plasma was measured.

Results-The activity of cNOS was lower in cirrhotic compared with non-cirrhotic subjects for both liver and omentum. Hepatic and omental iNOS activities did not differ significantly between the two groups. Portal $\left(\mathrm{NO}_{2}+\mathrm{NO}_{3}\right)$ was threefold higher in cirrhotic than non-cirrhotic patients, but no differences were observed in systemic venous samples from the two groups.
\end{abstract}

Conclusions-The activity of cNOS is diminished in the cirrhotic human liver. The resultant decrease in constitutive NO release may promote an increase in the intrahepatic portal vascular resistance. Elevated portal venous $\left(\mathrm{NO}_{2}+\mathrm{NO}_{3}\right)$ indicates enhanced splanchnic vascular release of NO in cirrhotic patients, but the absence of increased NOS activity in the mesenteric vasculature suggests differential regulation of NO synthesis within the splanchnic vascular bed.

(Gut 1999;44:749-753)

Keywords: cirrhosis; constitutive nitric oxide synthase; inducible nitric oxide synthase; nitric oxide; portal hypertension

University Department of Surgery, Royal Free Hospital School of Medicine, London, UK B R Davidson

Correspondence to: Dr Mathie.

Accepted for publication 1 December 1998
Cirrhosis is a diffuse process characterised widespread fibrosis and regenerative nodule formation in the liver. An increase in the intrahepatic resistance to portal venous flow is an important factor in the development and maintenance of portal hypertension (PHT) associated with this condition. ${ }^{1}$ Enhanced con- tractility of the hepatic perisinusoidal stellate cells (also called lipocytes or Ito cells) has been implicated as one cause of increased hepatic sinusoidal resistance in the cirrhotic liver. ${ }^{2}$ Lipocyte contractility is regulated by a counterbalance of the effects of agents such as endothelin ${ }^{3-5}$ which promote contraction of the lipocytes, and smooth muscle relaxing agents such as nitric oxide (NO). ${ }^{67} \mathrm{~A}$ decrease in NO activity may therefore promote PHT through an increase in the hepatic sinusoidal resistance. This hypothesis is supported by studies indicating reduced NO production in the cirrhotic rat liver. ${ }^{89}$

In addition to elevated intrahepatic resistance, abnormal dilatation in the mesenteric vascular bed, with decreased responsiveness to vasoconstrictor agents, is involved in the pathogenesis of PHT. ${ }^{1}$ This implies increased activity of an endogenous vasodilatory agent or agents, several candidates for which have been proposed. ${ }^{10}$ The principal one of these is NO and its role in animal models of cirrhosis and PHT has been extensively reviewed. ${ }^{11}{ }^{12}$ However, NO synthesis and release in the liver and splanchnic vasculature of human subjects with cirrhosis and PHT has not been previously reported.

NO is a highly reactive free radical which is synthesised by a family of enzymes (the nitric oxide synthases, NOS) through the L-arginine-NO pathway. ${ }^{13-15}$ In the healthy state, NO is released continuously by the vascular endothelium through the action of a constitutive isoform of NOS (cNOS), which requires calcium for initiation of its activity, ${ }^{16}$ and exerts a basal dilator tone on the underlying vascular smooth muscle. This action of $\mathrm{NO}$ is crucial in the maintenance of normal vascular tone, and mice lacking the gene for cNOS exhibit severe systemic hypertension. ${ }^{17}$ In contrast, a calcium independent inducible isoform of NOS (iNOS) is not a normal cellular constituent but is expressed in many different cell types, including hepatocytes, Kupffer cells, and vascular smooth muscle, after stimulation with bacterial endotoxin or cytokines. ${ }^{13-15} \mathrm{NO}$ is rapidly inactivated in tissues by oxidation to its metabolites nitrite and nitrate, which readily diffuse into the circulation. The total release of NO may therefore be assessed by measuring the plasma concentration of these metabolites. The capacity for a tissue to generate NO may be gauged by measuring the activities of cNOS and iNOS.

The involvement of NO in the pathogenesis of PHT associated with liver cirrhosis suggests

Abbreviations used in this paper: $\mathrm{NO}$, nitric oxide; NOS, nitric oxide synthase; PHT, portal hypertension. 
the possibility of modulating endogenous $\mathrm{NO}$ activity to therapeutic advantage. However, the results derived from rodent models of cirrhosis require confirmation in human subjects prior to their therapeutic application. Consequently, the aim of this study was to investigate the activities of cNOS and iNOS in the liver and mesenteric vasculature and the release of $\mathrm{NO}$ in the splanchnic and systemic circulations of patients suffering from cirrhosis and PHT.

\section{Methods}

PATIENTS

The study group consisted of 14 patients (eight men, six women; aged 42-67 years) with end stage cirrhosis of the liver who underwent orthotopic liver transplantation. All patients were categorised as Child's grade C, with portal hypertension confirmed by the presence of oesophageal varices on upper gastrointestinal endoscopy. The control group comprised nine non-cirrhotic patients (three men, six women; aged 44-67 years) undergoing liver resection for metastases from colorectal adenocarcinomas. There was no evidence of portal hypertension in the control group of patients. Portal pressure was measured in five cirrhotic patients (21.8 (4.5) $\mathrm{mm} \mathrm{Hg}$ ) and four control patients (10.3 (3.2) $\mathrm{mm} \mathrm{Hg} ; \mathrm{p}=0.008)$. Individuals with sepsis and those on nitrovasodilator therapy were excluded from the study.

Systemic blood samples were collected from a central venous line, immediately prior to the induction of anaesthesia. Intraoperatively, a blood sample was obtained directly from the portal vein. All blood samples were collected in heparinised glass tubes, immediately centrifuged at $2000 \mathrm{~g}$ for 10 minutes, and the plasma stored at $-20^{\circ} \mathrm{C}$. A biopsy specimen of a vascular portion of the greater omentum was obtained at an early stage in the operation in all patients. We considered such specimens to be representative of the mesenteric macro- and microvasculature, as ethical constraints did not permit us to obtain biopsy specimens of the mesenteric blood vessels in patients undergoing liver surgery. In the study group, a biopsy specimen was taken from the cirrhotic liver immediately after the hepatectomy was completed; in the control group, specimens were taken from normal tissue at the periphery of the resected liver specimen and (in four cases) from liver tumour. The omental biopsy specimen and a portion of each liver specimen were stored in liquid nitrogen for subsequent enzymatic assay. The remaining liver tissue was fixed in $10 \%$ formalin for histopathological examination.

Permission was granted by the ethics committees of the Royal Free Hampstead NHS Trust and the Hammersmith Hospitals NHS Trust for these studies.

BIOCHEMICAL ASSAY OF NITRIC OXIDE SYNTHASE ACTIVITY

This method, a modification of that previously described by Bredt and Snyder, ${ }^{18}$ measures the conversion of radiolabelled L-arginine to $\mathrm{L}$-citrulline, the equimolar coproduct of $\mathrm{NO}$ in the reaction catalysed by NOS, and has been optimised and validated in our laboratory. ${ }^{19}$ Hepatic and omental tissues were homogenised in nine volumes of $25 \mathrm{mM}$ HEPES buffer ( $\mathrm{pH} 7.4$ ) containing $1 \mathrm{mM}$ dithiothreitol, $50 \mathrm{mM}$ sucrose, $5 \mu \mathrm{g} / \mathrm{ml}$ leupeptin, 10 $\mu \mathrm{g} / \mathrm{ml}$ pepstain A, $10 \mu \mathrm{g} / \mathrm{ml}$ bestatin, $10 \mu \mathrm{g} / \mathrm{ml}$ chymostatin, $125 \mu \mathrm{g} / \mathrm{ml}$ soybean trypsin inhibitor, and $100 \mu \mathrm{g} / \mathrm{ml}$ phenylmethylsulphonyl fluoride. The homogenates were then centrifuged at $15000 \mathrm{~g}$ for three minutes and the supernatants were separated for assay. A $100 \mu \mathrm{l}$ aliquot of supernatant was added to $100 \mu \mathrm{l}$ of $25 \mathrm{mM}$ HEPES reaction buffer ( $\mathrm{pH} \mathrm{7.4)} \mathrm{con-}$ taining $1 \mathrm{mM}$ dithiothreitol, $20 \mu \mathrm{M}$ tetrahydrobiopterin, $10 \mu \mathrm{M}$ flavin adenine dinucleotide, $10 \mu \mathrm{M}$ flavin mononucleotide, $1 \mathrm{mM}$ nicotinamide adenine dinucleotide phosphate reduced form, $2 \mu \mathrm{M}$ L-arginine, $5 \mathrm{mCi} / \mathrm{ml}$ ${ }^{3} \mathrm{H}$-L-arginine, $8 \mathrm{mM}$ L-valine, $10 \mathrm{U} / \mathrm{ml}$ calmodulin, and $2 \mathrm{mM}$ calcium chloride. In order to measure the activity of the calcium independent isoform of NOS, calcium chloride and calmodulin were omitted and $2 \mathrm{mM}$ EDTA was included in the buffer. The mixtures were then incubated at $37^{\circ} \mathrm{C}$ for 30 minutes and the reaction terminated by adding $200 \mu \mathrm{l}$ of $0.2 \mathrm{M}$ sodium acetate buffer ( $\mathrm{pH}$ 5.2) containing 2 $\mathrm{mM}$ EDTA and $0.5 \mathrm{mM}$ citrulline. Lipopolysaccharide stimulated rat liver tissue was used as a positive control for iNOS activity as virtually all the NOS activity measured in this sample was calcium independent with negligible calcium dependent activity. All assays on liver and omental tissues were performed in triplicate on two separate occasions, with minimal (less than $5 \%$ ) intra-assay and interassay variation; this provided internal positive controls for cNOS activity. In order to generate negative controls, liver and omental tissue homogenates were substituted with distilled water. All chemicals were obtained from Sigma Ltd (Dorset, UK), except ${ }^{3} \mathrm{H}$-L-arginine which was obtained from Amersham Life Science Ltd (Buckinghamshire, UK).

The L-citrulline formed during the reaction was separated from unreacted L-arginine by thin layer chromatography and the radioactivity in the L-arginine and L-citrulline bands counted by liquid scintillation counting. The percentage conversion of L-arginine to L-citrulline was calculated. The results obtained using the buffer containing calcium chloride represent the combined activity of both NOS isoforms, while the buffer containing EDTA represents the calcium independent inducible NOS activity. The activity of the constitutive isoform is the difference in the activities obtained in the two buffers.

MEASUREMENT OF PLASMA NITRITE PLUS NITRATE Plasma samples were thawed immediately prior to assay and deproteinised by the addition of two volumes of cold ethanol and incubation on ice for 30 minutes. Following centrifugation at $1700 \mathrm{~g}$ for 10 minutes, deproteinised plasma supernatant was assayed for total nitrite and nitrate concentrations using a nitric oxide analyser (model 270B NOA, Sievers Instruments Inc., USA), as previously described. ${ }^{19}$ This is a highly sensitive method for measuring $\mathrm{NO}$ and 
Table 1 Activities of the constitutive and inducible isoforms of nitric oxide synthase (cNOS and iNOS, respectively)

\begin{tabular}{llll}
\hline & $\begin{array}{l}\text { Cirrhotic patients } \\
(n=14)\end{array}$ & $\begin{array}{l}\text { Non-cirrhotic } \\
\text { patients }(n=9)\end{array}$ & p Value \\
\hline Liver & & & \\
$\quad$ cNOS & $3.21(0.55)$ & $5.35(0.58)$ & 0.02 \\
$\quad$ iNOS & $2.90(0.63)$ & $4.51(0.94)$ & 0.15 \\
Omentum & & & \\
$\quad$ cNOS & $0.56(0.15)$ & $2.14(0.83)$ & 0.03 \\
iNOS & $1.18(0.27)$ & $0.97(0.17)$ & 0.49 \\
\hline
\end{tabular}

Results expressed as mean (SEM) in $\mathrm{pmol} / \mathrm{g} / \mathrm{min}$.

its metabolites in biological fluids. Reduction of nitrate to nitrite was performed by using 0.1 $M$ vanadium chloride in $1 \mathrm{M}$ hydrochloric acid at $95^{\circ} \mathrm{C}$. All samples were assayed in triplicate. A standard curve was established with serial dilutions $\left(10^{-3}\right.$ to $\left.10^{-6} \mathrm{~mol} / \mathrm{l}\right)$ of sodium nitrate. The concentrations of NO metabolites in the samples were determined by comparison with the standard curve. All chemicals used in this assay procedure were obtained from Sigma.

STATISTICAL ANALYSIS

The statistics software package SPSS 6.0 was used. Summary statistics are reported as mean (SEM). Student's $t$ test for independent samples was used to compare data in the cirrhotic and control groups. The paired samples $t$ test was used to compare pairs of liver tumour and matched normal liver tissue. A value of $p<0.05$ was regarded as statistically significant in all tests.

\section{Results}

Histopathology confirmed alcohol induced cirrhosis in nine patients, postnecrotic cirrhosis in three patients, and primary biliary cirrhosis in two patients in the study group. In the control group, all liver resection margin biopsy specimens were histologically normal and the four liver tumour specimens were confirmed as adenocarcinoma metastases.

NITRIC OXIDE SYNTHASE ACTIVITY

The activity of cNOS was substantially lower in cirrhotic liver in comparison to histologically normal liver from the control group $(\mathrm{p}=0.02$; table 1). However, there was no significant difference in iNOS activity between cirrhotic and normal liver tissue $(\mathrm{p}=0.15$; table 1$)$.

In biopsy specimens of vascular portions of the greater omentum, considered representative of the mesenteric vasculature, the activity of cNOS was significantly lower in cirrhotic patients in comparison to that in similar tissues from patients in the control group $(p=0.03$; table 1). Activity of iNOS in the same tissue from cirrhotic patients did not differ from that observed in samples from the control group $(\mathrm{p}=0.49$; table 1$)$.

Nitric oxide synthase activity was also examined in four pairs of liver tumours and matched normal liver tissue from the resection margin,

Table 2 Concentration of nitrite + nitrate $\left(\mathrm{NO}_{2}+\mathrm{NO}_{3}\right)$

\begin{tabular}{llll}
\hline & Cirrhotic patients $(n=14)$ & Non-cirrhotic patients $(n=9)$ & $p$ Value \\
\hline Portal $\left(\mathrm{NO}_{2}+\mathrm{NO}_{3}\right)$ & $40.68(7.16)$ & $14.16(6.28)$ & 0.007 \\
Systemic $\left(\mathrm{NO}_{2}+\mathrm{NO}_{3}\right)$ & $23.19(7.45)$ & $24.25(6.30)$ & 0.90 \\
\hline
\end{tabular}

Results expressed as mean (SEM) in $\mu \mathrm{mol} / 1$. in order to investigate whether NOS activity was altered in the peritumourous normal tissues used as controls. The activity of cNOS in the liver tumours was significantly lower than that in matched normal liver tissue $(2.42$ (0.58) versus $6.17 \quad(0.67) \quad \mathrm{pmol} / \mathrm{g} / \mathrm{min}$; $\mathrm{p}=0.02)$. In contrast, the activity of iNOS appeared similar in the tumours and matched normal tissues (6.35 (1.04) versus $6.50(0.54)$ $\mathrm{pmol} / \mathrm{g} / \mathrm{min} ; \mathrm{p}=0.93)$.

PLASMA NITRITE + NITRATE

The concentration of nitrite + nitrate in the portal venous plasma of cirrhotic patients was threefold greater than that in non-cirrhotic control patients $(p=0.007$; table 2$)$. The systemic venous concentrations of nitrite + nitrate were, however, similar in the cirrhotic and control groups of patients $(\mathrm{p}=0.90$; table 2$)$.

\section{Discussion}

Our data show notably lower cNOS activity in cirrhotic liver tissue obtained from patients who underwent orthotopic liver transplantation compared with that in histologically normal liver tissue from patients who underwent liver resection. NOS activity in cirrhotic human liver has not previously been reported. Our findings corroborate the results of experimental studies in animal models of cirrhosis and portal hypertension. ${ }^{89}$ In a rat model of secondary biliary fibrosis induced by common bile duct ligation, Zimmermann and colleagues $^{8}$ detected by semiquantitative immunohistochemistry a substantial reduction in cNOS expression in hepatocytes. More recently, Rockey and $\mathrm{Chung}^{9}$ have reported a $75 \%$ decrease in cNOS activity by the citrulline assay in isolated sinusoidal endothelial cells from a rat model of carbon tetrachloride induced cirrhosis. Depletion of constitutively expressed NO in the cirrhotic liver is consistent with the finding that the intrahepatic portal vascular bed of the cirrhotic liver exhibits hyper-reactivity to vasoconstriction by noradrenaline $^{20}$ and to sympathetic nerve stimulation, ${ }^{21}$ in contrast to the hyporesponsiveness to vasoconstrictor agents known to occur in other regions of the peripheral vasculature in cirrhosis. ${ }^{22}$ There is increasing evidence that NO (whether of hepatic parenchymal or vascular origin) contributes to the normal regulation of the hepatic microvascular resistance via its relaxing influence on the perisinusoidal stellate cells. ${ }^{2}$ Reduced hepatic NOS activity, with a resultant decrease in $\mathrm{NO}$ release, is likely to facilitate the counteracting influence of the potent vasoconstricting agent, endothelin 1, especially in the cirrhotic liver, ${ }^{5}$ and thereby bring about an increase in the sinusoidal resistance. Our data support the hypothesis that reduced intrahepatic synthesis and release of NO may be implicated in the pathogenesis of elevated intrahepatic portal vascular resistance in the cirrhotic human liver. The cause of diminished cNOS activity in the cirrhotic liver remains unclear, but may reflect a response to hepatocellular damage as suggested by Rockey and Chung'; this concept is 
supported by our findings of decreased cNOS activity in liver tumours in comparison to normal liver tissue.

Experimental studies in rodent models of cirrhosis have detected unaltered hepatic iNOS activity. ${ }^{23}{ }^{24}$ Our results from human tissue tend to corroborate these findings. However, the detection of iNOS activity in "control" tissue suggests upregulation of enzymatic expression compared with the basal state. Indeed, in four liver tumours studied, iNOS activity was found to be similar to that in the matched histologically normal tissues, indicating that iNOS activity was stimulated in both the tumour and peritumoural "normal" tissue. This may be consequent to the elevated levels of circulating cytokines known to accompany malignancy, ${ }^{25}$ the stress of a major operation, and possibly endotoxaemia due to bowel handling. Thus, we cannot discount the possibility that iNOS expression may in fact be stimulated in cirrhotic liver, given that our control tissues may have provided an overestimate of the true baseline. Inclusion of a third group of patients without any liver pathology might have further clarified this issue; however, it was deemed ethically impermissible to biopsy the liver in patients undergoing non-resectional operations.

Vallance and Moncada ${ }^{26}$ hypothesised that enhanced vascular NO synthesis, as a result of iNOS induction in the blood vessel walls due to the endotoxaemia associated with liver cirrhosis, may be responsible for the splanchnic and systemic vasodilatation found in advanced stages of this disease. However, experimental studies in animal models of cirrhosis and PHT have provided conflicting data, with evidence both for ${ }^{27-31}$ and against ${ }^{232432} 33$ the occurrence of increased iNOS activity in the mesenteric vascular bed. Our data do not support the hypothesis of elevated iNOS activity in the mesenteric vasculature (as represented by biopsies of well vascularised greater omentum) of patients with cirrhosis. However, the effect of colorectal cancer metastatic to the liver on the mesenteric expression of iNOS is unknown and may have altered the expression from normal in our control tissues. Intriguingly, cNOS activity was notably reduced in the omental tissues obtained from our cirrhotic patients. This corroborates previous pharmacological data from our laboratory implying decreased endothelial cNOS activity in isolated mesenteric vascular preparations from cirrhotic rats. ${ }^{31}$

The NOS activity data imply that NO synthesis may remain unaltered, or may even be decreased, in the mesenteric blood vessels of cirrhotic patients. This suggests that enhanced activity of an endogenous vasodilator other than NO is responsible for the pathogenesis of mesenteric vasodilatation associated with cirrhosis. Several agents, such as glucagon, ${ }^{34}$ prostaglandins, ${ }^{35}$ atrial natriuretic peptide, ${ }^{36}$ vasoactive intestinal peptide, ${ }^{37}$ false neurotransmitters, ${ }^{38}$ and platelet-activating factor $^{39}$ have been implicated, and their roles require further investigation. It remains possible, however, that NO synthesis is upregulated differentially in regions of the splanchnic vasculature other than the mesenteric blood vessels, as discussed below.

A roughly threefold rise in the concentration of NO metabolites was detected in the portal venous plasma of patients with liver cirrhosis and portal hypertension in comparison to that in non-cirrhotic patients having no evidence of PHT. These data indicate that NO release is substantially enhanced in the splanchnic vasculature of patients with liver cirrhosis and portal hypertension and provide indirect evidence of increased NOS functional activity in the splanchnic venous drainage territory. A previous study reporting a positive correlation between blood flow and nitrate concentration in the portal venous circulation of cirrhotic patients corroborates these findings. ${ }^{40}$ The anatomical site of enhanced NO synthesis and release, however, remains unclear. There is evidence to suggest that NOS activity may be preferentially upregulated in discrete anatomical regions rather than diffusely throughout the splanchnic bed; for example, in a rat model of portal vein ligation cNOS activity was upregulated only in the jejunum but not in the stomach. ${ }^{24}$ Other investigators have reported increased NO production from cNOS in the gastric mucosa ${ }^{41}$ and increased iNOS and cNOS expression in the oesophageal mucosa. ${ }^{42}$ In addition, there is at least one report of increased iNOS and cNOS expression in the gastric mucosa of cirrhotic patients. ${ }^{43}$ It is possible, therefore, that the elevated concentrations of NO metabolites in the portal venous plasma of the cirrhotic patients reflect increased NOS activity in the splanchnic viscera of these patients.

Our study has shown no difference in concentrations of NO metabolites in the peripheral venous plasma of patients with liver cirrhosis compared with those in our control patients. Several previous studies have reported higher concentrations of nitrite and nitrate in the peripheral venous plasma of patients with cirrhosis compared with healthy volunteers. ${ }^{44} 45$ However, enhanced activity of iNOS in liver tumours may have resulted in increased release of NO into the systemic circulation of our control group as compared with healthy individuals. Indeed, plasma concentrations of nitrite and nitrate in the peripheral venous plasma of patients with hepatocellular carcinoma based on cirrhosis have been reported to be higher than those in equivalent samples from patients with cirrhosis without this complication. ${ }^{46}$ Our results indicate that plasma concentration of NO metabolites is similar in the peripheral plasma of patients with cirrhosis and in those with secondary liver tumours within a noncirrhotic liver.

In summary, this study has shown decreased activity of cNOS in the cirrhotic human liver. This phenomenon may be a central event in the development of increased intrahepatic vascular resistance and portal hypertension in patients with advanced cirrhosis. In addition, we have shown increased release of NO in the splanchnic circulation of cirrhotic patients, though the absence of increased NOS activity in omental biopsy specimens representative of 
the mesenteric vasculature suggests that $\mathrm{NO}$ synthesis may be differentially regulated within the splanchnic vascular bed.

We are grateful to Professor Julia Polak for providing use of the $\mathrm{NO}$ analyser in the Department of Histochemistry, Imperial College School of Medicine, Hammersmith Hospital, London, UK.

1 Groszmann RJ, Jensen JE. Pathophysiology of portal hypertension. In: Kaplowitz N, editor. Liver and biliary diseases, 2nd ed. Baltimore: Williams \& Wilkins, 1996:494-504.

2 Rockey DC. The cellular pathogenesis of portal hypertension: stellate cell contractility, endothelin, and nitric oxide. Hepatology 1997;25:2-5.

3 Housset C, Rockey DC, Bissell DM. Endothelin receptors in rat liver: lipocytes as contractile target for endothelin 1 . Proc Natl Acad Sci USA 1993;90:9266-70.

4 Bauer M, Paquette NC, Zhang JX, et al. Chronic ethanol consumption increases hepatic sinusoidal contractile re-
sponse to endothelin in the rat. Hepatology 1995;22:156576 .

5 Rockey DC, Fouassier L, Chung JJ, et al. Cellular localisation of endothelin-1 and increased production in liver injury in the rat: potential for autocrine and paracrine effects on stellate cells. Hepatology 1998;27:472-80.

6 Kawada N, Tran Thi TA, Klein H, et al. The contraction of hepatic stellate (Ito cells) stimulated by vasoactive substances. Possible involvement of endothelin 1 and nitric oxide in the regulation of the sinusoidal tonus. Eur $f$ Biochem 1993;213:815-23.

7 Rockey DC, Chung JJ. Inducible nitric oxide synthase in rat hepatic lipocytes and the effect of nitric oxide on lipocyte contractility. F Clin Invest 1995;95:1199-206.

8 Zimmermann H, Kurzen P, Klossner W, et al. Decreased constitutive hepatic nitric oxide synthase expression in secondary biliary fibrosis and its changes after Roux-en-Y choledocho-jejunostomy in the rat. F Hepatol 1996;25:56773 .

9 Rockey DC, Chung JJ. Reduced nitric oxide production by endothelial cells in cirrhotic rat liver: endothelial dysfunction in portal hypertension. Gastroenterology 1998;114:34451.

10 Stark ME, Szurszewski JH. Role of nitric oxide in gastrointestinal and hepatic function and disease. Gastroenterology 1992;103:1928-49.

11 Bomzon A, Blendis LM. The nitric oxide hypothesis and the hyperdynamic circulation in cirrhosis. Hepatology 1994;20 1343-9.

12 Sogni P, Moreau R, Gadano A, et al. The role of nitric oxide in the hyperdynamic circulatory syndrome associated with portal hypertension. 7 Hepatol 1995;23:218-24.

13 Moncada S, Higgs A. The L-arginine-nitric oxide pathway. N Engl F Med 1993;329:2002-12.

14 Kuo PC, Schroeder RA. The emerging multifaceted roles of nitric oxide. Ann Surg 1995;221:220-35.

15 Sarela AI, Mathie RT. The role of nitric oxide in surgical practice. Surgery 1996;14:154-6.

16 Kuchan MJ, Frangos JA. Role of calcium and calmodulin in flow-induced nitric oxide production in endothelial cells. Am f Physiol 1994;266:C628-36.

17 Huang PL, Huang Z, Mashimo H, et al. Hypertension in mice lacking the gene for endothelial nitric oxide synthase. Nature 1995;377:239-42.

18 Bredt DS, Snyder SH. Isolation of nitric oxide synthase, a calmodulin-requiring enzyme. Proc Natl Acad Sci USA 1990;87:682-5.

19 Al-Mufti RA, Williamson RCN, Mathie RT. Increased nitric oxide activity in a rat model of acute pancreatitis. Gut 1998;43:564-70.

20 Mathie RT, Ralevic V, Burnstock G. Portal vascular responsiveness to sympathetic stimulation and nitric oxide in cirrhotic rats. F Hepatol 1996;25:90-7.

21 Zimmermann T, Gardemann A, Machnik G, et al. Metabolic and hemodynamic responses of bivascularly perfused rat liver to nerve stimulation, noradrenaline, acetylcholine and glucagon in thioacetamide-induced microtylcholine and glucagon in thioacetamide-ind

22 Ryan J, Sudhir K, Jennings G, et al. Impaired reactivity of the peripheral vasculature to pressor agents in alcoholic cirrhosis. Gastroenterology 1993;105:1167-72.
23 Fernández M, García-Pagán JC, Casadevall $\mathrm{M}$, et al. Evidence against a role for inducible nitric oxide synthase in the hyperdynamic circulation of portal-hypertensive rats. Gastroenterology 1995;108:1487-95.

24 Kanwar S, Kubes P, Tepperman BL, et al. Nitric oxide synthase activity in portal-hypertensive and cirrhotic rats. $\mathcal{F}$ Hepatol 1996;25:85-9.

25 Balkwill F, Osborne R, Burke F, et al. Evidence for tumour necrosis factor/cachectin production in cancer. Lancet 1987; ii:1229-32.

26 Vallance P, Moncada S. Hyperdynamic circulation in cirrhosis: a role for nitric oxide? Lancet 1991;337:776-8.

27 Pizcueta MP, Piqué JM, Bosch J, et al. Effects of inhibiting nitric oxide biosynthesis on the systemic and splanchnic circulation of rats with portal hypertension. BrF Pharmacol 1992;105:184-90.

28 Sieber CC, Lopez-Talavera JC, Groszmann RJ. Role of nitric oxide in the in vitro splanchnic vascular hyporeactivity in ascitic cirrhotic rats. Gastroenterology 1993;104:17504.

29 Niederberger M, Martin P-Y, Ginès P, et al. Normalization of nitric oxide production corrects arterial vasodilation and hyperdynamic circulation in cirrhotic rats. Gastroenterology 1995;109:1624-30.

30 Cahill PA, Foster C, Redmond EM, et al. Enhanced nitric oxide synthase activity in portal hypertensive rabbits. Hepatology 1995;22:598-606.

31 Mathie RT, Ralevic V, Moore KP, et al. Mesenteric vasodilator responses in cirrhotic rats: a role for nitric oxide? Hepaology 1996;23:130-6.

32 Sogni P, Moreau R, Ohsuga M, et al. Evidence for normal nitric oxide-mediated vasodilator tone in conscious rats with cirrhosis. Hepatology 1992;16:980-3.

33 Heinemann A, Stauber RE. The role of inducible nitric oxide synthase in vascular hyporeactivity of endotoxintreated and portal hypertensive rats. Eur F Pharmacol 1995; 278:87-90.

34 Benoit JN, Zimmermann B, Premen AJ, et al. Role of glucagon in the splanchnic hyperemia of chronic portal hypertension. Am F Physiol 1986;251:G674-7.

35 Zipser RD, Hoefs JC, Speckhart PF, et al. Prostaglandins: modulators of renal function and pressor resistance in chronic liver disease. F Clin Endocrinol Metab 1979;48:895900 .

36 Fernández-Cruz A, Marco J, Cuadrado LM, et al. Plasma levels of atrial natriuretic peptide in cirrhotic patients. Lancet 1985;ii: $1439-40$

37 Kitamura S, Yoshida T, Said SI. Vasoactive intestinal peptide: inactivation in liver and potentiation in lung of anaesthetised dogs. Proc Soc Exp Biol Med 1975;148:25-9.

38 Fisher JE, Baldessarini RJ. False neurotransmitters and hepatic failure. Lancet 1971;ii:75-80.

39 Caramelo C, Fernández-Gallardo S, Santo JC, et al. Increased levels of platelet-activating factor in blood from patients with cirrhosis of the liver. Eur $\mathcal{F}$ Clin Invest 1987; 17:7-11

40 Shijo $\mathrm{H}$, Yokoyama $\mathrm{M}$, Ota $\mathrm{K}$, et al. Nitrate kinetics in patients with compensated cirrhosis: correlation with hemodynamics. Am f Gastroenterol 1996;91:2190-4.

41 Ohta M, Tanoue K, Tarnawski AS, et al. Overexpressed nitric oxide synthase in portal-hypertensive stomach of rat: a key to increased susceptibility to damage? Gastroenterology 1997;112:1920-30.

42 Tanoue K, Ohta M, Tarnawski AS, et al. Portal hypertension activates the nitric oxide synthase genes in the esophageal mucosa of rats. Gastroenterology 1996;110:549-57.

43 El-Newihi HM, Kanji VK, Mihas AA. Activity of gastric mucosal nitric oxide synthase in portal hypertensive gastropathy. Am f Gastroenterol 1996;91:535-8.

44 Guarner C, Soriano G, Tomas A, et al. Increased serum nitrite and nitrate levels in patients with cirrhosis: relationship to endotoxemia. Hepatology 1993;18:1139-43.

45 Albillos A, Rossi I, Cacho G, et al. Enhanced endotheliumdependent vasodilation in patients with cirrhosis. Am $\mathcal{F}$ Physiol 1995;268:G459-64.

46 Moriyama A, Masumoto A, Nanri H, et al. High plasma concentration of nitrite/nitrate in patients with hepatocellular carcinoma. Am f Gastroenterol 1997;92:1520-3. 